\title{
Suppression of Fragmentation in Mass Spectrometry
}

\author{
Supporting information
}

\section{Siddihalu Lakshitha Madunil, ${ }^{\#}$ Totaro Imasaka ${ }^{\dagger, \ddagger}$ and Tomoko Imasaka ${ }^{\sharp *}$}

\#Faculty of Design, Kyushu University, 4-9-1, Shiobaru, Minami-ku, Fukuoka 815-8540, Japan

${ }^{\dagger}$ Kyushu University,744 Motooka, Nishi-ku, Fukuoka 819-0395, Japan

‡Hikari Giken, Co., 2-10-30, Sakurazaka, Chuou-ku, Fukuoka 810-0024, Japan

Table of contents:

Fig. S1. Absorption spectra for cis- and trans-4-methycyclohexanols.

Fig. S2. Absorption spectra for molecular ions of cis- and trans-4-methycyclohexanols.

Fig. S3. Signal intensity of $[\mathrm{M}]^{+}$for cis- and trans-4-methylcyclohexanols at different UV wavelengths.

Fig. S4. Ionization mechanism of 4-methycyclohexanols.

Fig. S5. Signal intensity of $[\mathrm{M}]^{+}$for cis- and trans-4-methylcyclohexanols measured at different NIR wavelengths.

Fig. S6. Absorption spectra of fundamental and overtone vibrational bands calculated for cis- and trans-4methylcyclohexanols in the IR region.

Table S1. Cartesian coordinates of the atoms in cis-4-methylcyclohexanol.

Table S2. Cartesian coordinates of the atoms in trans-4-methylcyclohexanol.

Table S3. Keldysh parameter $(\gamma)$ and electron kinetic energy calculated at different wavelengths for $c i s$ - and trans4-methylcyclohexanols.

Refs. S1-S4 

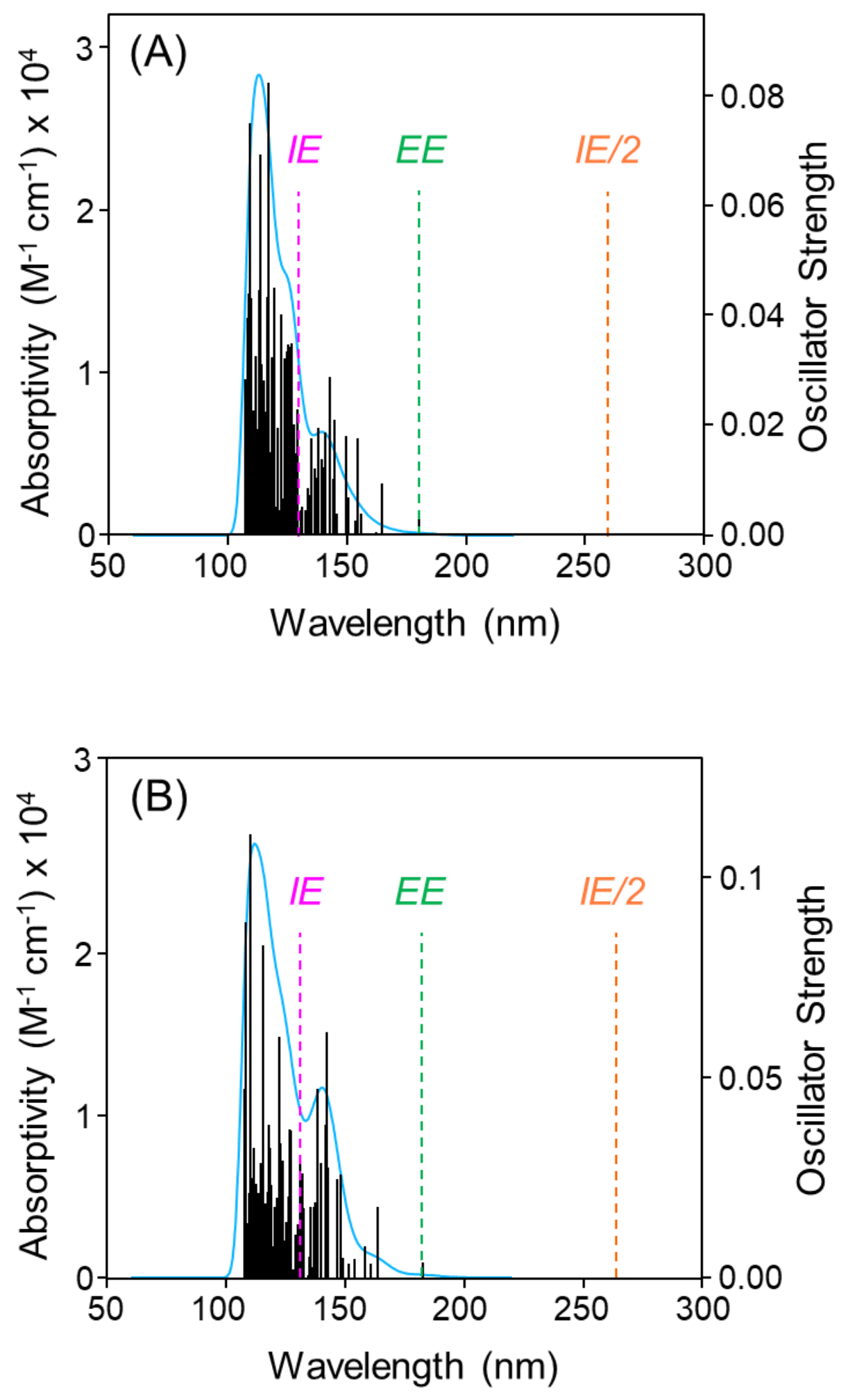

Figure S1. Absorption spectra for (A) cis- and (B) trans-4-methycyclohexanols. EE, excitation energy, IE, ionization energy, $I E / 2$, half value of $I E$ 

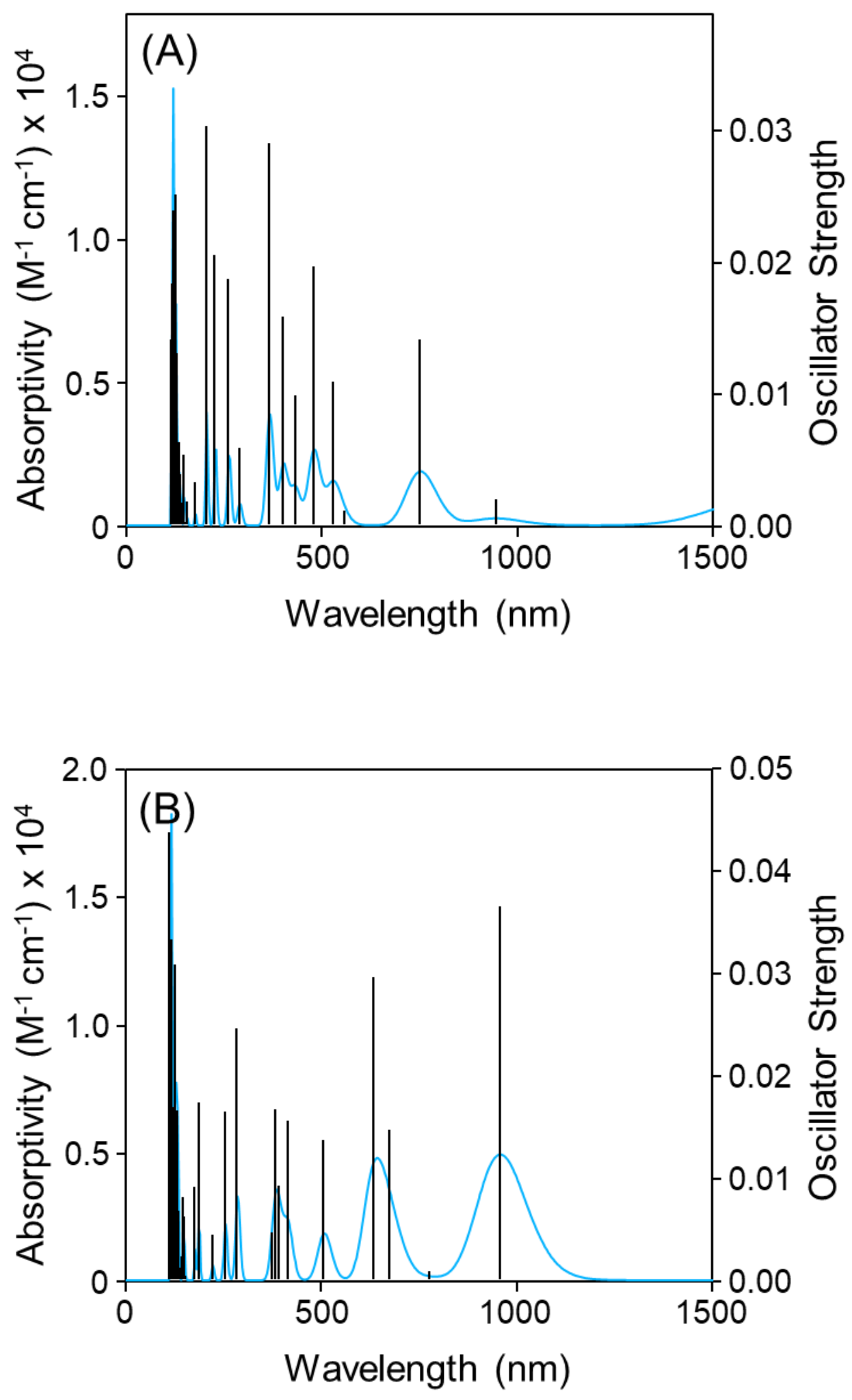

Figure S2. Absorption spectra for molecular ions of (A) cis- and (B) trans-4-methycyclohexanols. 


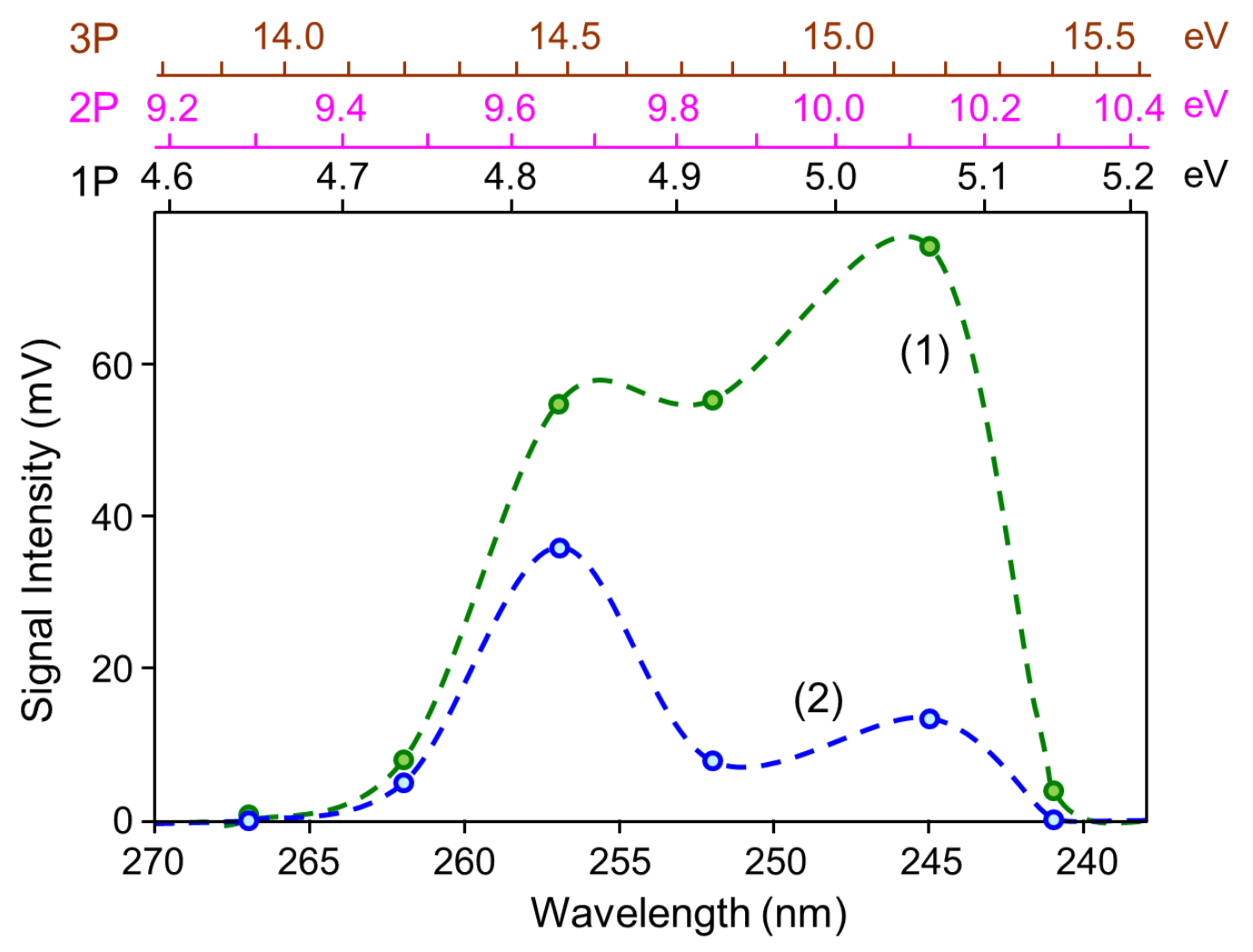

Figure S3. Signal intensity of $[\mathrm{M}]^{+}$for (1) cis- and (2) trans-4-methylcyclohexanols at different UV wavelengths. 

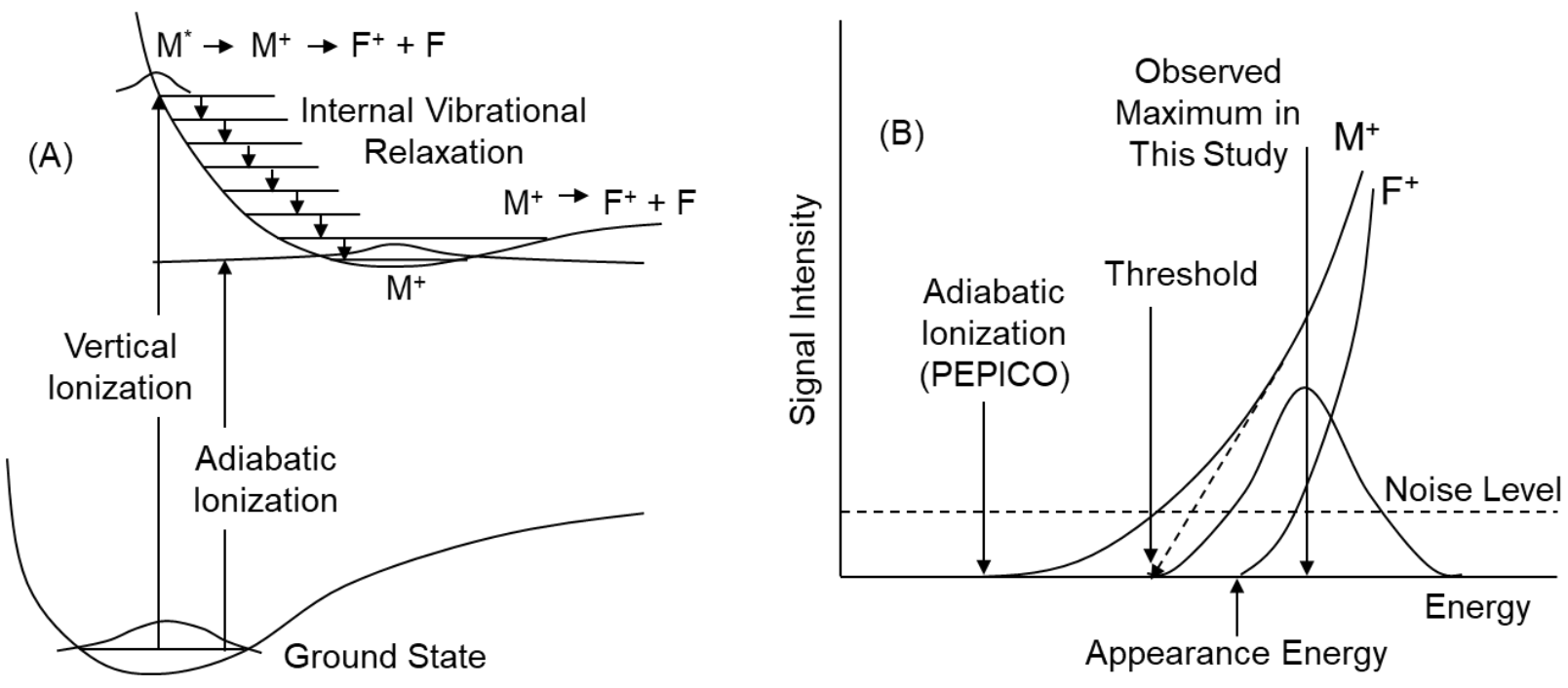

Figure S4. (A) Ionization mechanism of 4-methycyclohexanols. A molecule in the ground state is two-photon excited to form a neutral molecule in the superexcited state $\left(\mathrm{M}^{*}\right)$, which is ionized by ejecting an electron as is referred to as "vertical ionization". Due to a sufficient energy in the ionic state, a molecular ion can dissociate to form many fragment ions. The molecular ion in highly-excited vibrational levels can be relaxed by internal vibrational relaxation to reach a stable (but shallow) potential curve of a dissociation coordinate, providing a molecular ion in the mass spectrum. A molecular ion can be formed by adiabatic ionization (see reference $\mathrm{S} 1$ for schemes of vertical and adiabatic ionizations), which can be measured by photoelectron-photoion coincidence (PEPICO) spectroscopy. ${ }^{\mathrm{S} 2-\mathrm{S} 4}$ However, the Franck Condon factor of this transition is very (or negligibly) small due to very different configurations for the ground states in the neutral and ionic forms of a flexible molecule such as 4-methylcyclohexanol. For this reason, a contribution of adiabatic ionization is considered to be small for 4methylcyclohexanol. (B) Photoionization spectrum. The signal intensity of a molecular ion appears above the threshold of the curve for $\mathrm{M}^{+}$and disappears after the rapid increase of the curve for $\mathrm{F}^{+}$by dominant occurrence of the fragment ion. The spectral width observed in the data is expanded by several other reasons (see the main text for the explanation of Figure 3(B)). 


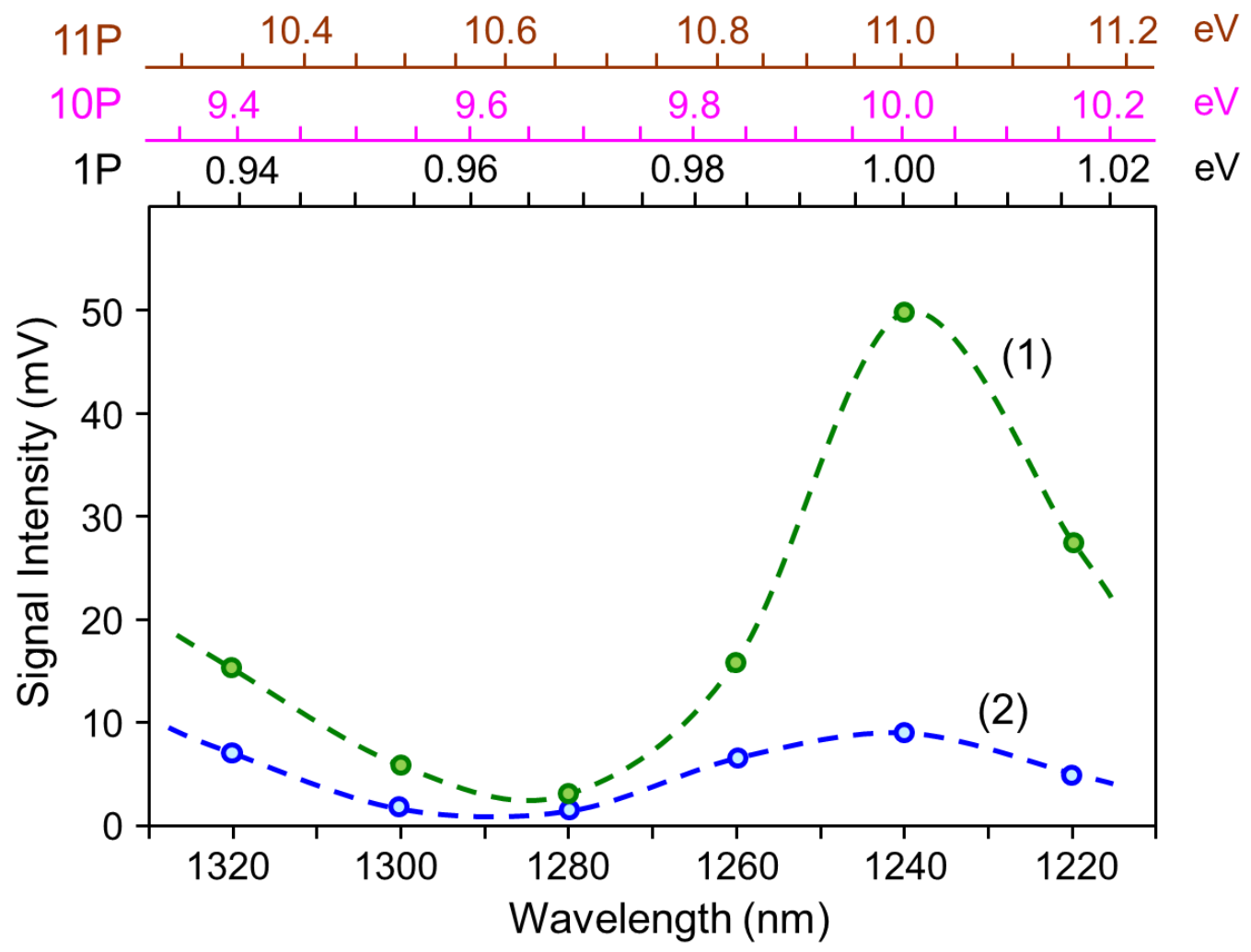

Figure S5. Signal intensity of $[\mathrm{M}]^{+}$for (1) cis- and (2) trans-4-methylcyclohexanols measured at different NIR wavelengths. 

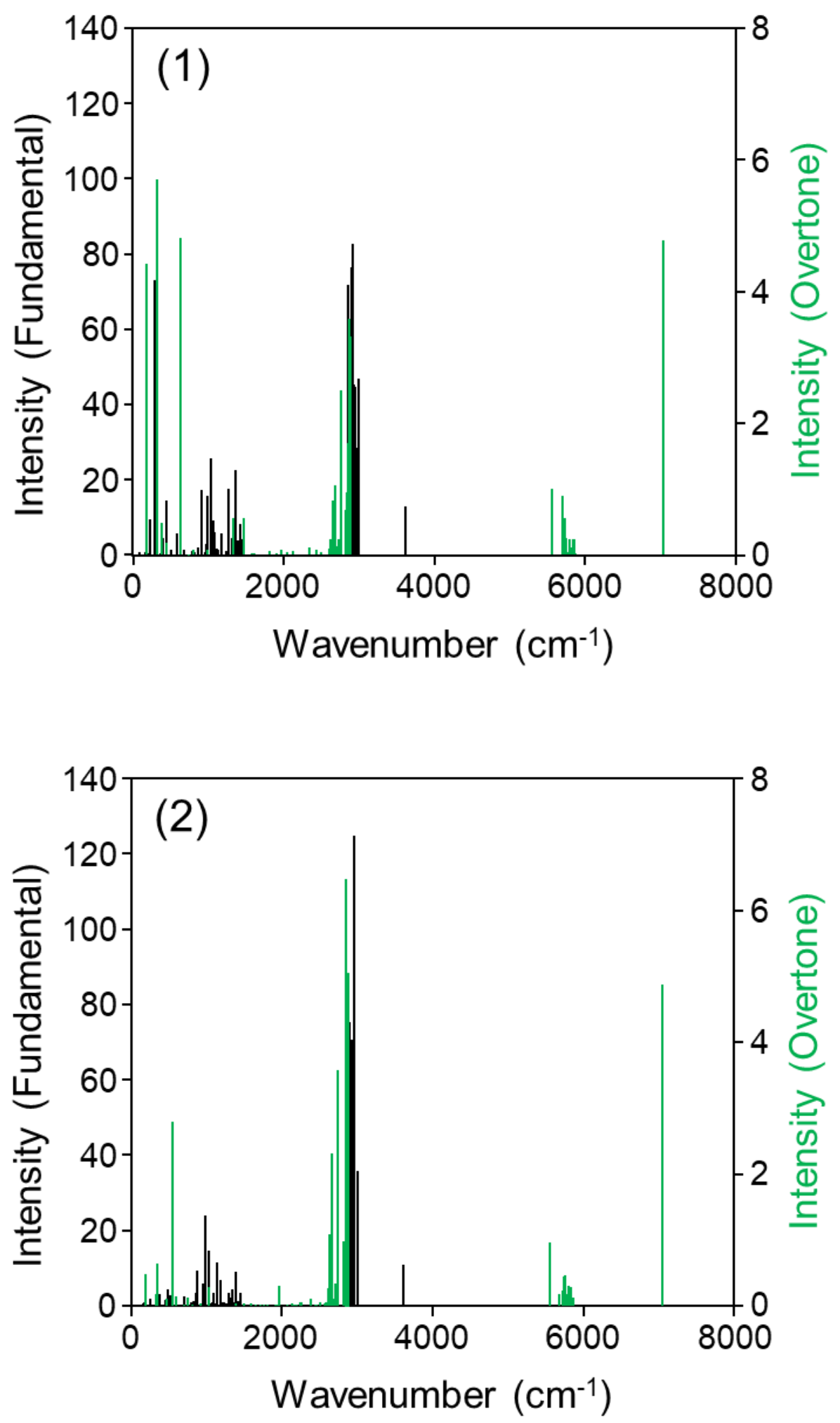

Figure S6. Absorption spectra of fundamental and overtone vibrational bands calculated for (1) cis- and (2) trans-4methylcyclohexanols in the IR region. 
Table S1. Cartesian coordinates of the atoms in cis-4-methylcyclohexanol.

\begin{tabular}{|c|c|c|c|}
\hline $\mathrm{C}$ & -0.98987 & 1.0256 & -0.8076 \\
\hline $\mathrm{C}$ & 0.45105 & 1.41749 & -0.42432 \\
\hline $\mathrm{C}$ & 1.42052 & 0.20099 & -0.28988 \\
\hline $\mathrm{C}$ & 0.79159 & -1.06067 & -0.91394 \\
\hline $\mathrm{C}$ & -0.58115 & -1.42931 & -0.31734 \\
\hline $\mathrm{C}$ & -1.48195 & -0.19756 & -0.03582 \\
\hline $\mathrm{H}$ & 0.83227 & 2.12771 & -1.17652 \\
\hline $\mathrm{H}$ & 0.42419 & 1.96391 & 0.5312 \\
\hline $\mathrm{H}$ & -1.05475 & 0.79532 & -1.88513 \\
\hline $\mathrm{H}$ & 0.67423 & -0.89204 & -1.99898 \\
\hline $\mathrm{H}$ & 1.48273 & -1.91533 & -0.8166 \\
\hline $\mathrm{H}$ & -0.45458 & -1.98498 & 0.62829 \\
\hline $\mathrm{H}$ & -1.09815 & -2.1181 & -1.00703 \\
\hline $\mathrm{H}$ & -2.52091 & -0.42669 & -0.34446 \\
\hline $\mathrm{H}$ & -1.67236 & 1.87097 & -0.62422 \\
\hline $\mathrm{O}$ & -1.47861 & 0.17263 & 1.35037 \\
\hline $\mathrm{H}$ & -1.78139 & -0.5944 & 1.85747 \\
\hline $\mathrm{H}$ & 2.33411 & 0.4212 & -0.86955 \\
\hline $\mathrm{C}$ & 1.85148 & -0.02431 & 1.16786 \\
\hline $\mathrm{H}$ & 2.51856 & -0.89874 & 1.25957 \\
\hline $\mathrm{H}$ & 2.39826 & 0.8534 & 1.55123 \\
\hline $\mathrm{H}$ & 0.97664 & -0.17666 & 1.81795 \\
\hline
\end{tabular}

Unit, Angstrom. 
Table S2. Cartesian coordinates of the atoms in trans-4-methylcyclohexanol. Unit, Angstrom.

\begin{tabular}{|c|c|c|c|}
\hline $\mathrm{C}$ & 0.86907 & -1.06345 & -0.87274 \\
\hline $\mathrm{C}$ & -0.54443 & -1.27482 & -0.2807 \\
\hline C & -1.15305 & 0.00787 & 0.33719 \\
\hline $\mathrm{C}$ & -0.63767 & 1.24511 & -0.4143 \\
\hline $\mathrm{C}$ & 0.89449 & 1.3968 & -0.2956 \\
\hline $\mathrm{C}$ & 1.63387 & 0.0459 & -0.15402 \\
\hline $\mathrm{H}$ & -1.21083 & -1.64805 & -1.07906 \\
\hline $\mathrm{H}$ & -0.5134 & -2.06066 & 0.49032 \\
\hline $\mathrm{H}$ & 0.80206 & -0.78404 & -1.93838 \\
\hline $\mathrm{H}$ & -0.92357 & 1.15607 & -1.47937 \\
\hline $\mathrm{H}$ & -1.1362 & 2.15665 & -0.0435 \\
\hline $\mathrm{H}$ & 1.15167 & 2.01908 & 0.58096 \\
\hline $\mathrm{H}$ & 1.28601 & 1.93589 & -1.17532 \\
\hline $\mathrm{H}$ & 2.64564 & 0.14072 & -0.59618 \\
\hline $\mathrm{H}$ & 1.44895 & -1.99872 & -0.82836 \\
\hline $\mathrm{H}$ & -0.78344 & 0.07964 & 1.37472 \\
\hline $\mathrm{O}$ & 1.75023 & -0.36694 & 1.21373 \\
\hline $\mathrm{H}$ & 2.19271 & 0.34576 & 1.69693 \\
\hline C & -2.68161 & -0.05518 & 0.37198 \\
\hline $\mathrm{H}$ & -3.03251 & -0.96198 & 0.89252 \\
\hline $\mathrm{H}$ & -3.11078 & 0.81693 & 0.89316 \\
\hline $\mathrm{H}$ & -3.10226 & -0.0752 & -0.64912 \\
\hline
\end{tabular}


Table S3. Keldysh parameter $(\gamma)$ and electron kinetic energy calculated at different wavelengths for cis- and trans-4methylcyclohexanols.

\begin{tabular}{|c|c|c|c|}
\hline Wavelength (nm) & Isomer & $\gamma$ & Kinetic energy $(\mathrm{eV})$ \\
\hline \multirow[t]{2}{*}{1220} & cis- & 1.33 & 8.42 \\
\hline & trans- & 1.32 & \\
\hline \multirow[t]{2}{*}{1240} & cis- & 1.33 & 8.43 \\
\hline & trans- & 1.32 & \\
\hline \multirow[t]{2}{*}{1260} & cis- & 1.33 & 8.42 \\
\hline & trans- & 1.32 & \\
\hline \multirow[t]{2}{*}{1280} & cis- & 1.34 & 8.40 \\
\hline & trans- & 1.33 & \\
\hline \multirow[t]{2}{*}{1300} & cis- & 1.33 & 8.42 \\
\hline & trans- & 1.32 & \\
\hline \multirow[t]{2}{*}{1320} & $c i s-$ & 1.33 & 8.42 \\
\hline & trans- & 1.32 & \\
\hline \multirow[t]{2}{*}{241} & cis- & 4.22 & - \\
\hline & trans- & 4.19 & \\
\hline \multirow[t]{2}{*}{245} & cis- & 4.22 & - \\
\hline & trans- & 4.19 & \\
\hline \multirow[t]{2}{*}{252} & cis- & 4.22 & - \\
\hline & trans- & 4.19 & \\
\hline \multirow[t]{2}{*}{257} & $c i s-$ & 4.22 & - \\
\hline & trans- & 4.19 & \\
\hline \multirow[t]{2}{*}{262} & $c i s-$ & 4.22 & - \\
\hline & trans- & 4.19 & \\
\hline \multirow[t]{2}{*}{267} & cis- & 4.22 & - \\
\hline & trans- & 4.19 & \\
\hline
\end{tabular}




\section{References}

(S1) Ivanov, M. V.; Wang, D.; Zhang, D.; Rathore, R.; Reid, S. A. Vertical vs. adiabatic ionization energies in solution and gas-phase: probing ionizationinduced reorganization in conformationallymobile bichromophoric actuators using photoelectron spectroscopy, electrochemistry. Phys. Chem. Chem. Phys. 2018, 20, 25615-25622.

(S2) Wikipedia, "Photoelectron photoion coincidence spectroscopy"; https://en.wikipedia.org/wiki/ Photoelectron_photoion_coincidence_spectroscopy.

(S3) Baer, T. Photoelectron-photoion coincidence methods in mass spectrometry (PEPICO). Encyclopedia of Spectroscopy and Spectrometry, 1999, pp. 1831-1839.

(S4) Hemberger, P.; Trevitt, A. J. Ross, E.; da Silva, G. Direct observation of para-xylylene as the decomposition product of the meta-xylyl radical using VUV synchrotron radiation. J. Phys. Chem. Lett. 2013, 4, 2546-2550 